\title{
Self-controlled irrigation system
}

\author{
Tuheli Bhattacharya ${ }^{1}$, Shramona Chakraborty ${ }^{1}$, Rahul Roy ${ }^{1}$, Abhishek Sarkar $^{2}$, Suvanjan \\ Bhattacharyya $^{3 *}$ \\ ${ }^{1}$ Computer Science Engineering Department, MCKV Institute of Engineering, Howrah 711204, \\ West Bengal \\ 2 Electronics and Communication Engineering Department, MCKV Institute of Engineering, \\ Howrah 711204, West Bengal \\ ${ }^{3}$ Mechanical Engineering Department, MCKV Institute of Engineering, Howrah 711204, West \\ Bengal
}

Email: suvanjanr@gmail.com

\begin{abstract}
Farming is a major occupation for many people in countries like India, and it is the life line for entire population of the world. Water is the backbone of the farming industry. As per India is censured, lots of water gets wasted due to many reasons. Smart Irrigation System serves a way to minimize this wastage of water in agricultural fields. The system incorporates the features of IoT. The supply of water in the fields is controlled by sensing the requirement of water in the fields using various sensors and switching the pump on and off automatically according to the requirement.
\end{abstract}

Keywords: Farming, Irrigation, IoT, Sensors, Pump, Water Resources, Automation.

\section{INTRODUCTION}

Agriculture is the backbone of Indian economy. It is the one of the major occupation for many people in India. Out of $2 / 3^{\text {rd }}$ water found in the Earth, only $3.5 \%$ is fresh water that can be put into use in any day-to-day activities. About $85 \%$ of this available freshwater is used in agriculture and $5-30 \%$ of this percentage gets wasted on a regular basis due to many reasons. Over the years different means of irrigation has evolved to minimize this wastage of water in agricultural lands. However, one of the major problem that still remains, leading to wastage of water, is the lack of proper knowledge of the farmers about the soil moisture content, and hence the requirement of the amount of water in the agricultural soil. More often than not it is the carelessness of the farmers that results in wastage of water. So, considering the concern of water wastage, there is an urgent need to create strategies based on science and technology for sustainable use of water, including technical, agronomic, managerial and institutional improvements [1]. An alternative parameter to determine crop irrigation needs is estimating plant evapotranspiration (ET). ET is affected by weather parameters, including solar radiation, temperature, relative humidity, wind speed, and crop factors, such as stage of growth, variety and plant density, management elements, soil properties, pest, and disease control [2]. Systems based on ET have been developed that allow water savings of up to $42 \%$ on timebased irrigation schedule [3]. An electromagnetic sensor to measure soil moisture was the basis for developing an irrigation system at a savings of $53 \%$ of water compared with irrigation by sprinklers in an area of $1000 \mathrm{~m}^{2}$ of pasture [4]. A reduction in water use under scheduled systems also have been achieved, using soil sensor and an evaporimeter, which allowed for the adjustment of irrigation to the daily fluctuations in weather or volumetric substrate moisture content [5].

Thus, farmer has to follow the irrigation timetable meticulously and some supervisor needs to be present there for whole day, it is always the possibility that more water may be given to the crop or in some cases lesser amount of water may be given, which may affect the yield [6].

In this system, an automated irrigation system based on Arduino and sensors is presented that can be used to minimize the water wastage in agricultural fields and minimize the human intervention in irrigation. In this system, resistive soil moisture sensors are placed deep inside the soil at different parts of the agricultural fields that reads the moisture content of the soil instantaneously. These sensors return a value based on the soil moisture content to an Arduino device which in turn operates the pump. These values differ depending on the moisture content of the soil. The Arduino device is the heart of the system. It checks the values of the sensors. Whenever the soil gets dry enough the Arduino device switches on the pump, thereby causing water to flow in the fields. When the soil gets adequate amount of water, the system switches off the pump. The values provided 
by the sensors at which the pump will get switched on and off will differ according to the types of soils and the kind of crops that are getting harvested. These values will be set at the time of installation and a proper training would be required for the farmers to change these values in the future.

\section{SELF CONTROLLED IRRIGATION SYSTEM}

As shown in Figure 1, the self-controlled irrigation system hereby reported, consisted of one component that will operate the pumps in the agricultural fields. As shown in Figure 2 the quantity of water present in the agricultural soil will be read instantaneously using the soil moisture sensors implanted deep inside the soil at various positions. The heart of this system is the Arduino device that will receive the values (analog) read by the sensors. Based on the type of crop planted in the field and the type of soil, a cut-off value will be set in the Arduino system. The Arduino will compare this value with the ones provided by the sensors e.g. Figure 2 . The output from the Arduino system will be a signal that will switch on the pump, provided the values read by the sensor are greater than the cut-off value e.g. Figure 2.

\subsection{Introduction of equipment used}

Arduino-ATmega328P Microcontroller: Arduino/Genuino Uno is a microcontroller board based on the ATmega328P. It has 14 digital input/output pins (of which 6 can be used as PWM outputs), 6 analog inputs, a $16 \mathrm{MHz}$ quartz crystal, a USB connection, a power jack, an ICSP header and a reset button. The device has the following features:

1) An operating voltage of 5V D.C. This is easily available by using voltage regulator IC.

2) Input voltage limit of 6-20V. However, usage of 7-12V of input voltage is recommended.

3) 14 digital input/output pins, of which 6 provide PWM $\mathrm{I} / \mathrm{O}$ and 6 analog input pins.

4) $20 \mathrm{~mA}$ DC current per I/O pin and $50 \mathrm{~mA}$ DC current for $3.3 \mathrm{~V}$ pin.

5) $32 \mathrm{~KB}$ (ATmega328P) Flash Memory, of which $0.5 \mathrm{~KB}$ is used by boot loader.

6) $2 \mathrm{~KB}$ (ATmega328P) SRAM and 1KB (ATmega328P) EEPROM.

7) $16 \mathrm{MHz}$ Clock Speed and 13 LED_BUILTIN.

In this system A0, A1, A2, A4 act as sensor interface pins pin 10 and 11 are output pin initially both are set low and after a certain value pin 10 is made high. Vin is used to drive both L239D driver and the 9v pump.

Soil Moisture Sensor: - There are different means of detecting soil moisture of the farm in this system basically the resistance of the soil is being measured hence copper wire that are connected with comparator to form a mesh of sensors are used in this system, the advantage of this copper wire over garden sensor is that, sensors are generally of longer length and can easily be installed in irrigation field as per requirements. LM339-N is used as the comparator, LM339N series consists of four independent precision voltage comparators with an offset voltage specification as low as 2 $\mathrm{mV}$ maximums for all four comparators. These comparators also have a unique characteristic in that the input commonmode voltage range includes ground, even though they are operated from a single power supply voltage.
L293D Motor Driver Chip: L293D is a 16-pin motor driver IC which can control a set of two DC motors simultaneously in any direction.

1) There are two Enable pins on 1293d, pin 1 and pin 9, for driving the motor. For driving the motor left, pin 1 needs to be high. And for driving the motor right, pin 9 needs to be high.

2) There are 4 input pins for 1293d, pin 2 and 7 on the left and pin 15 and 10 on the right. Left input pins will regulate the rotation of motor connected across left side and right input for motor on the right-hand side. The motors are rotated on the basis of the inputs provided across the input pins as LOGIC 0 or LOGIC 1.

3) Internal operating voltage of $5 \mathrm{~V}$ (VCC); pin 16.

4) Maximum voltage of $36 \mathrm{~V}$ and maximum current of 600 $\mathrm{mA}$ per channel to drive the motor.

In this system, Pin 2 and 7 acts as input pin connected from output pin (10 and 11) of Arduino and 3 and 6 are output pins that are basically used to drive the pump.

Since DC pump is used the other side of the IC chip can be used.

Submersible Sump Pumps (9v): - Submersible (underwater) sump pumps are the best used when water is taken from a shallow water source to a single outlet with high volume. The shallow water source, can be a pond, ditch, reservoir, etc. that is 20 feet deep or less [7]. The single outlet is typically a garden hose. The common use for the sump pump would be to water a small garden with a hose. (It's most common use however is to pump water out of flood basements.)

Input Voltage: DC $3.5 \mathrm{~V}-9 \mathrm{~V}$

Power: 3W

Power supply requirements: - Adapter(DC)

Output voltage $=9 \mathrm{~V}$

Output current $=1 \mathrm{~A}$

User Interface: - The threshold value for the system according to type of soil, crop being cultivated and weather will be set using this interface, in future this will be implemented using an android application, through which a farmer can set the threshold value of this system and even if will get updates and notification about moisture content of the soil.

Figure 1 shows the block reprenstation of the above described components.

\section{MATHEMATICAL ANALYSIS}

\subsection{Units and values}

Soil used: Dry soil

Region: Tropical region

Sensor Value Description:

- Dry Soil: 950 to 1050 (resistive value of soil)

- Humid Soil: 590 to 950 (resistive value of soil)

- Soil having adequate water for plantation: 350 to 590 (resistive value of soil)

Cut-Off Value Used:590 (resistive value of soil)

This cut-off value will change according to type of soil, types of crop, and weather conditions. 


\section{FIGURES AND DIAGRAMS}

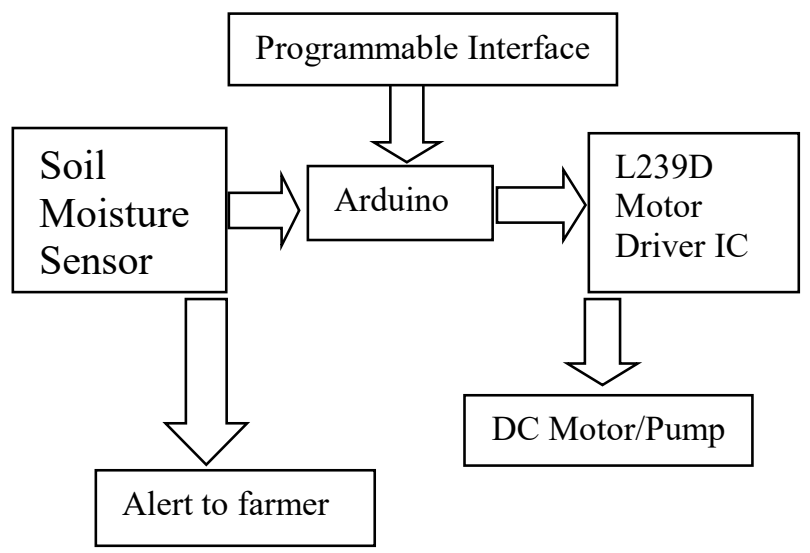

Figure 1. (Block diagram of the system)

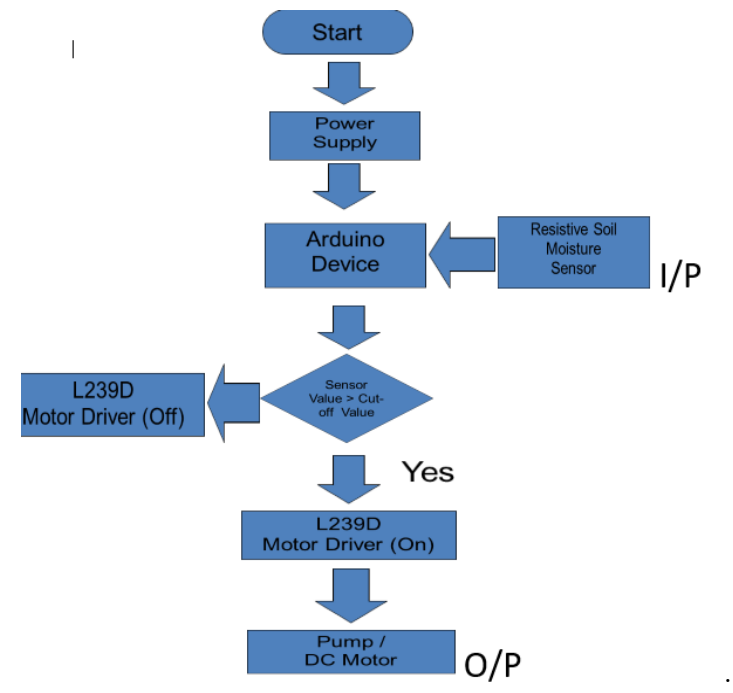

Figure 2. (Flow diagram of the system)

\section{RESULT AND DISCUSSION}

Readings: (Values indicates Resistive value of soil)

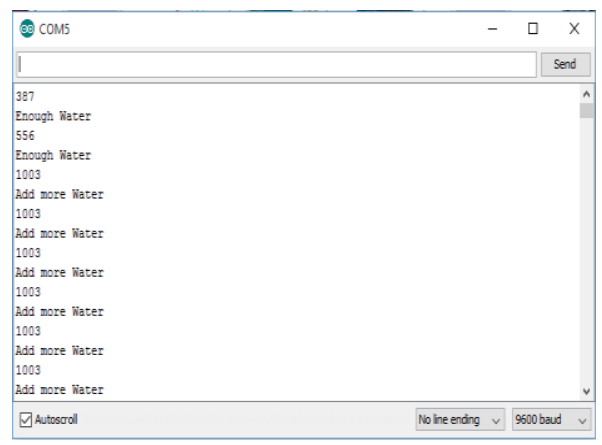

Figure 3. (Output of the system above cutoff)

As tropical soil is used, it gives a value less than 590 (resistive value of soil) when it has adequate amount of moisture content in it on the other hand it gives a value greater than 590 (resistive value of soil) when it lacks enough water for proper growth of plants or crops. Hence, the cut-off value is fixed as 590 (resistive value of soil) for the D.C Motor/Pump to run accordingly. As shown in Figure 3 when the value given by the sensor is greater than 590 (resistive value of soil), the Arduino will provide signal to the Motor Driver and it will turn the Motor/Pump On. Water is provided to the soil. Again, as shown in Figure 4 when the sensor gives a value less than 590 (resistive value of soil), the Arduino will again provide signal to the Motor Driver and it will turn the Motor/Pump Off.

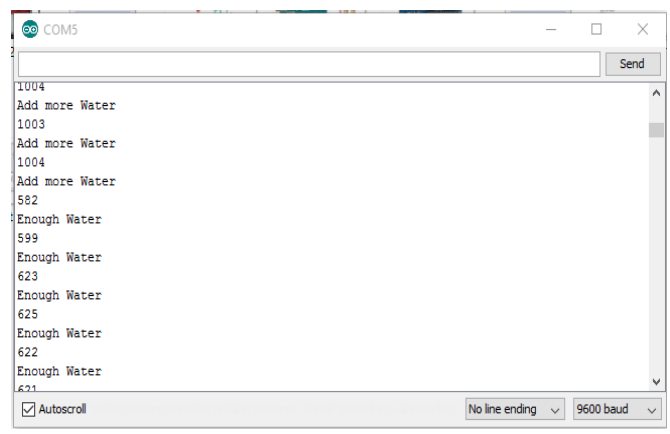

Figure 4. (Output of the system below cutoff)

\section{CONCLUSIONS}

This system has several benefits and it can be easily operated without any human intervention. It overcomes the limitations of the existing irrigation system by using water efficiently. It operates with less manpower. The system is cost efficient, saves water and improves the growth of plants.

Considering these results obtained after prototype testing, the overall performance of the designed system is as required and have met the designing objectives. As manual irrigation systems waste a lot of water and time for farmers, this system will help them to save their time also to save water and cost as it irrigates only when water is needed in the soil and it does all that process automatically.

\section{ACKNOWLEDGMENT}

The authors would like to thank Prof. (Dr.) Parasar Bandyopadhyay, Director, MCKV INSTITUTE OF ENGINEERING and Prof. Suvanjan Bhattacharyya Assistant Professor, Mechanical Engineering Department, MCKV Institute of Engineering.

\section{REFERENCES}

[1] Jury W.A., Vaux H.J. (2007). The emerging global water crisis: managing scarcity and conflict between water users, $A d v$. Agronomy, Vol. 95, pp. 1-76.

[2] O'Shaughnessy S.A., Evett S.R. (2010). Canopy temperature based system effectively schedules and controls center pivot irrigation of cotton, Agricult. Water Manag., Vol. 97, No. 9, pp. 1310-1316.

[3] Allen R.G., Pereira L.S., Raes D., Smith M. (1998). Crop evapotranspiration-guidelines for computing crop water requirements, FAO Irrigation and Drainage Paper, No. 56, Rome, Italy: FAO.

[4] Davis S.L., Dukes M.D. (2010). Irrigation scheduling performance by evapotranspiration-based controllers, Agricult. Water Manag., Vol. 98, No. 1, pp. 19-28. DOI: 10.1016/j.agwat.2010.07.006 
[5] Migliaccio K.W., Schaffer B., Crane J.H., Davies F.S. (2010). Plant response to evapotranspiration and soil water sensor irrigation scheduling methods for papaya production in south Florida, Agricult. Water Manag., Vol. 97, No. 10, pp. 1452-1460. DOI: $\underline{10.1016 / j . a g w a t .2010 .04 .012}$
[6] Gonzalez R.A., Struve D.K., Brown L.C. (1992). A computer-controlled drip irrigation system for container plant production, HortTechnology, Vol. 2, No. 3, pp. 402-407.

[7] Byelich B., Cook J., Rowley C. (2013). Small acreage irrigation guide. 